\title{
A LA MEMORIA DE JUAN GARCÍA PONCE (1932-2003) \\ Claudia Albarrán*
}

El pasado 27 de diciembre murió Juan García Ponce en su casa de Coyoacán, asistido apenas por el personal de servicio que usualmente lo ayudaba a sobrellevar la esclerosis múltiple, una enfermedad que lo condenó a la silla de ruedas desde 1967 (en ese entonces los médicos le dijeron que sólo le quedaban seis meses de vida: tenía 35 años) y que fue inmovilizando paulatinamente todos sus músculos y las articulaciones de su cuerpo hasta dejarlo prácticamente sin habla. Y digo 'apenas' porque quienes lo quisimos hubiéramos deseado estar allí, acompañándolo en esos minutos fatales de agonía y asfixia o, al menos, hubiéramos querido que ese día, a esa hora precisa, Eugenia, la persona que lo atendió fielmente durante más de treinta años, no hubiera salido al mercado minutos antes de que se produjera el paro respiratorio, fatal y definitivo.

Había pasado las vacaciones navideñas fuera de México y, como muchos otros, me había olvidado de los problemas y las noticias, así que, al regreso, recién entrado enero, procuré estirar un poco más el descanso y el aislamiento, así que conecté la grabadora telefónica para no responder llamadas. Llegó, pues, el día de Reyes y, mientras mi hija Ana abría emocionada sus regalos, alcancé a escuchar el timbre del teléfono y la voz de Patricia González, mujer de Huberto Batis y buena amiga mía, que repetía titubeante: Juan murió.

\footnotetext{
* Centro de Lenguas, ITAM.
} 


\section{CLAUDIA ALBARRÁN}

La primera imagen que vino a mi mente para contrarrestar la noticia fue recordar la chispeante mirada de Juan, riendo feliz, a carcajadas, desde su silla de ruedas. Tiene una servilleta de tela muy blanca sobre el pecho, a modo de babero, que le cubre la corbata y el traje impecables, y que contrasta con sus cachetes y sus labios, perfectamente cubiertos de mole. Nos había invitado a cenar para conversar sobre literatura y, como a esas alturas de la enfermedad su voz era casi incomprensible, también había citado a María Luisa Herrera, su amanuense y amiga, quien amablemente nos ayudó a entender las palabras de Juan durante toda la noche.

Y es que Juan García Ponce era un hombre único y ejemplar en éste y otros muchos sentidos: podía estar sufriendo, podía estar incapacitado físicamente, podía tener el cuerpo llagado por las horas que pasaba inmóvil, recostado en su cama, ${ }^{1}$ pero se presentaba pulcro, trajeado y feliz, con los ojos brillantes y la mente clara, lista para sostener una conversación siempre cálida y excepcionalmente lúcida.

A su porte de caballero inglés y a su mirada traviesa, se le sumaban, sobre todo, dos cualidades extraordinarias que él sostuvo en pie hasta sus últimos días: la dignidad y la entrega apasionada.

Como primer exponente de una generación atormentada (la generación de la Casa del Lago, integrada por Tomás Segovia, Juan Vicente Melo, Inés Arredondo, José de la Colina, Salvador Elizondo y Huberto Batis, entre otros), que privilegió la calidad y promovió la universalidad de la literatura que se hacía en nuestro país (especialmente, durante los años sesenta), su papel fue esencial: traductor, guionista, dramaturgo, ensayista, cuentista, novelista, crítico de artes plásticas, promotor

${ }^{1}$ En un lindo artículo publicado recientemente, Huberto Batis menciona el doloroso y prolongado vía crucis al que Juan se sometía diariamente antes de salir de su recámara, para, luego, dictarle a María Luisa los textos que había rumiado y 'aprendido de memoria' durante sus largas horas de insomnio. Véase Huberto Batis, "El más firme y antiguo de mis amigos”, en Posdata (suplemento cultural de El Independiente), número 27, sábado 10 de enero de 2004, p. 5-7. 
cultural, fundador, director y colaborador de un montón de instituciones, de revistas y suplementos culturales como Universidad de México, Revista Mexicana de Literatura, Cuadernos del Viento, La Palabra y el Hombre, México en la Cultura, La Cultura en México y Diagonales.

Como intelectual, Juan sostuvo infinidad de polémicas tanto personales como públicas con escritores, editores, grupos de poder, mafias y camarillas en defensa de sus ideas, de la libertad de pensamiento, de la autonomía y el respeto hacia la buena literatura, independientemente de las nacionalidades, los cuatachismos, los gremios y las cuestiones éticas o morales, las cuales más de una vez le cerraron las puertas, le negaron becas o premios y le impidieron publicar sus comentarios. Nada fue lo suficientemente fuerte para silenciarlo: si la progresiva e irreversible enfermedad había fracasado en su intento de anularlo físicamente, encerrándolo en las estrechas paredes de su casa de Coyoacán -que, no obstante, él transformó en su paraíso, en biblioteca de Babel, en museo de arte contemporáneo, en orgía perpetua, en santuario personal de sus múltiples mujeres- nadie, salvo la muerte, podía anularlo.

Y es que la gran aliada con la que Juan contó para hacerle frente al confinamiento fue la literatura. La escritura de su propia obra (una de las más prolíficas de nuestras letras: más de cincuenta libros publicados, entre ensayos, teatro, cuentos, novelas, crítica de artes plásticas y un largo y afortunado etcétera), así como la lectura y el análisis de la obra de los escritores a los que él admiraba (como Georges Bataille, Pierre Klossowski, Thomas Mann y Robert Musil, de quienes escribió sendos tratados que no sólo nos permitieron leerlos por primera vez, sino comprenderlos gracias a su penetrante mirada) le dieron sentido, espacio, voz, cuerpo y movimiento a su vida, a su pensamiento.

Dedicado a la contemplación silenciosa de todo lo que lo rodeaba, lo inquietaba o lo emocionaba, Juan adquirió una sabiduría y una humildad pocas veces vistas en un intelectual de su altura: auxiliado por un atril y por la mano de su asistente, dedicó gran parte del día y la noche a la lectura y relectura constante de sus escritores preferidos, de sus amigos, aunque se entretuvo también con los textos de escritores jóvenes (muchas veces inexpertos), a quienes les dedicó su tiempo y con 


\section{CLAUDIA ALBARRÁN}

quienes sostuvo largas discusiones y conversaciones, siempre enriquecedoras.

Juan era así: un hombre accesible y a la vez exigente, sabio y humilde; generoso, pero nunca condescendiente. Odiaba la estupidez, la ignorancia, la actitud petulante, la hipocresía.

La primera vez que lo visité me recibió como si me conociera de toda la vida: me habían pedido que lo entrevistara para la revista Universidad de México, así que me armé de valor y lo llamé por teléfono para concertar una cita en su casa. Contrario a todas mis expectativas y prejuicios, aceptó inmediatamente y quedamos en vernos una semana después con "la condición -me dijo- de que llevara las preguntas por escrito”. Cuando llegué, estaba esperándome, acompañado de María Luisa. Comenzó, pues, la supuesta entrevista, aunque debo confesar que, gracias a ese encuentro, no sólo me volví una fiel admiradora de Juan y de su obra, sino que recibí una de las mejores lecciones de mi vida: A cada pregunta mía, él respondía, primero, cuestionando (afinando, matizando e incluso reformulando) la propia pregunta que acababa de hacerle, pero en su réplica no había ofensa ni ironía ni sarcasmo: con las reformulaciones no sólo intentaba enseñarme muy sutilmente el oficio, sino que eliminaba lo accesorio y le daba una dimensión mucho más profunda a ese encuentro, una dimensión que estaba al nivel de su inteligencia. Luego, respondía pausadamente y sin dudar, como si leyera, como si dentro de su mente tuviera escritas y bien redactadas las palabras. En varios momentos (y para responder de un modo más preciso) me pidió incluso que buscara en la estantería que estaba a mi espalda tal o cual libro: “Ábrelo en la página tal. Ve al segundo párrafo. Lee en voz alta lo que dice. Bien. Eso es textualmente lo que quiero responder. Ahora, cópialo.”2

Fue justamente esa vez, cuando escuché en sus propias palabras, sin ostentación, sin presunción, una frase que todavía hace eco en mi

2 Una de los fragmentos que me pidió ‘copiar' como respuesta a una de las preguntas era de Musil, y decía así: "Procurando una experiencia es como la creación literaria procura el conocimiento.” 
memoria y que, sin lugar a dudas, me hizo darme cuenta de que me encontraba frente a un ser monstruoso, excepcional: "Las obras artísticas -la literatura es una forma de arte- obedecen a una pura necesidad sin fin y cuyo principio es casi imposible situar de una manera específica y concreta. El artista se calla cuando, como dice Pavese en uno de sus últimos poemas, viene la muerte y le cierra los ojos.”3

Cuando, tres semanas más tarde, regresé a su casa con la entrevista publicada, con una botella de whisky y un puñado de globos de colores como forma de agradecimiento, simplemente me dijo: “Quiero pedirte un favor. Párate junto a María Luisa y déjame contemplarte así, en silencio, unos minutos.” Conocía las leyes de su hospitalidad, así que, desde luego, lo obedecí de inmediato.

Sé que el día que Huberto Batis y Armando Pereira presentaron su Autobiografía precoz en Bellas Artes el propio Juan pidió que, cuando muriera, lo velaran en el ISSSTE y que se tiraran sus restos al bote de la basura. Contradiciendo esta vez su último deseo (acaso su última broma, macabra y perversa), aseguro que nunca podremos olvidarlo: lo llevaremos siempre en la memoria.

${ }^{3}$ Cfr. Claudia Albarrán y Adriana Gutiérrez, "La literatura como necesidad sin fin. Entrevista a Juan García Ponce”, Universidad de México, núm. 489, octubre, 1991, p.14. 
